\title{
Quando se canta o conflito. Contribuições para a análise de desafios cantados
}

\author{
Allan de Paula Oliveira ${ }^{1}$ \\ Doutorando em Antropologia Social-PPGAS/UFSC
}

\begin{abstract}
RESUMO: Este texto apresenta reflexôes sobre o cururu, tipo de desafio cantado, praticado no interior de São Paulo. Partindo da transcrição de um desses conflitos poéticos, procura-se apontar aspectos da estrutura e performance do cururu enquanto embate entre dois cantadores que buscam se sobrepor por meio da palavra cantada. Ao mesmo tempo, observa-se como o cururu constitui uma atualização particular de um fenômeno social mais amplo: a troca. A partir daí, é possível pensar suas particularidades em relação a outras formas de desafios cantados, iluminando tanto o cururu quanto estes últimos.
\end{abstract}

PALAVRAS-CHAVE: cururu, desafios cantados, reciprocidade.

Este texto pretende ser uma contribuição ao estudo de um tipo de prática musical muito comum no Brasil: os desafios cantados. Praticados em todo o país, esses desafios aparecem nas mais diferentes formas: entre dois ritmistas, como na embolada alagoana; entre dois violeiros, como no repente nordestino; entre dois cantadores acompanhados por violas, como no cururu paulista. Para além de sua diversidade, neles há um ponto em comum: todo o evento gira em torno de dois oponentes, cujas armas consistem no canto, no humor, na palavra, e no qual um procura derrotar o outro diante de uma platéia. Há, portanto, uma com- 
Allan de Paula Oliveira. Quando se canta o conflito...

petição entre dois cantores que disputam a primazia em matéria de improviso cantado.

Se há uma competição, pode-se dizer que também há um conflito. Sigo aqui a afirmação de Simmel (1978, p. 23), para quem a competição é uma forma indireta de conflito, já que na competição a intenção não é eliminar o adversário mas, sim, atingir um objetivo comum antes dele. Simmel nos permite ir além de uma idéia simplista do conflito como unicamente agressão física, abrindo a possibilidade de analisá-lo em suas diferentes formas. Trata-se de uma concepção que vê no conflito uma forma positiva de sociação na medida em que ela integra indivíduos. Isto, no caso dos desafios cantados, é facilmente observável: há em torno dos desafios uma reunião não somente de cantadores, mas também de músicos e assistentes. Essa abordagem de Simmel, do conflito como forma positiva de sociação - a forma negativa seria a indiferença pura e simples -, inverte as abordagens mais comuns sobre o tema do conflito, visto como algo negativo, desagregador. Trata-se aqui de observar como um conflito, ou ainda, a ritualização dele, produz coesão no seio de um grupo.

Porém, os desafios cantados não se resumem a essa produção de uma conjunção social. São competições, o que significa que, ao mesmo tempo em que produzem uma integração entre indivíduos, esses fatos sociais também criam tensões, produzem verticalizações sociais. Assim, não se trata somente de observar o conflito em sua função integradora, mas de perceber como ele combina horizontalização e verticalização, articula coesão e tensão sociais. Qual seria o sentido disso, ou melhor, quais seriam os mecanismos pelos quais um conflito opera tais movimentos, é uma das questôes que este texto tenta refletir.

Para isso, apresentarei um pequeno estudo de caso, analisando o cururu, forma de canto improvisado, praticado no Centro-Sul do Brasil. Os dados indicados foram obtidos com base no trabalho de campo, 
Revista de Antropologia, São Paulo, USP, 2007, v. 50 No 1.

realizado no primeiro semestre de 2003, com cantadores de cururu de Piracicaba (SP). Aqui o exercício é refletir sobre uma manifestação singular de modo que ela ofereça aportes e elementos de análise de manifestações análogas, respeitando, obviamente, a singularidade de cada uma. Pretendo, assim, contribuir com um mínimo para o estudo destas formas musicais, os desafios cantados. Ao mesmo tempo, chamo a atenção para um exemplo de emulação que se dá por meio da palavra cantada, procurando alargar ainda mais o entendimento da idéia de conflito.

O cururu é uma forma de canto improvisado, praticado em áreas do Centro-Sul do Brasil, marcadamente aquelas de colonização paulista (sul de Minas, norte do Paraná, sul de Goiás, Mato Grosso, interior de São Paulo), e atualmente seu principal centro é Piracicaba (SP). ${ }^{2}$ Nessa cidade, inclusive, há um uso identitário em torno do cururu, e essa prática é apresentada como um dos símbolos do município, articulando em torno dela uma disputa de primazia entre municípios vizinhos. Desde a década de 1940, são comuns campeonatos de cururu que envolvem cantadores de toda a região do Médio Rio Tietê - que engloba cidades como Piracicaba, Tietê, Tatuí, Sorocaba, Conchas, Bofete, Botucatu e outras. ${ }^{3}$

Originado de adaptações jesuíticas das tradições ameríndias, o cururu envolve cantadores que se desafiam em seu poder de improviso, sendo acompanhados por violas. Em outras épocas, o canto versava somente sobre temas religiosos. No entanto, a partir dos anos 40, com a inserção do cururu no rádio, ganhou força a prática de improviso em que um cantador provoca o outro, fazendo gozaçôes e pilhérias. Dessas modalidades de improviso, duas se impuseram como as principais: o cantar na Bíblia e o canto de pau trocado. ${ }^{4} \mathrm{O}$ primeiro corresponde ao improviso sobre temas bíblicos; o segundo, sobre temas jocosos. Atualmente, é muito raro assistir a um cururu em que apareça somente uma dessas formas de improviso, o comum são cantorias em que essas modalidades 
Allan de Paula Oliveira. Quando se canta o conflito...

aparecem combinadas: canta-se uma estrofe para o santo e uma outra para gozar de outro cantador. ${ }^{5}$

O improviso no cururu segue rimas denominadas carreiras. Estas são indicadas por nomes que indicam a terminação silábica que irá ditar as rimas. Por exemplo, carreira do A para rimas em a, carreira do dia, para rimas em ia, carreira de São João, para rimas em ão, e assim por diante. Algumas carreiras são dificílimas e, por isso mesmo, muito raras: é o caso de carreiras como a de Santo Antônio (rimas em ônio) e de São Pedro (rimas em edro). Tais carreiras já denotam um capital simbólico que faz que o cantador que as use adquira, dentro grupo, uma visibilidade maior. Atualmente, as carreiras mais cantadas são somente a do dia e a de São João. Não há também um número fixo de versos, eles podem variar. Ouvi muitos improvisos com sete e nove versos - alguns autores fazem referências a improvisos com quadras, dado que não observei (cf. Araújo, 1964). Seja como for o número de estrofes, o importante é que elas sejam construídas em torno da carreira. Assim, uma estrofe de nove versos recebe a forma $\mathrm{bAbAdAcc} A$, na qual $\mathrm{A}$ corresponde à terminação silábica da estrofe.

O cururu ocorre o ano todo, geralmente em festas comunitárias, como quermesses e feiras, ou em festas religiosas, como as relacionadas à Folia do Divino, à Páscoa e ao Natal. Em Piracicaba, todo final de semana, ocorre pelo menos um cururu. Nesses eventos, costuma-se reunir de três a quatro cantadores, que se apresentam um de cada vez por cerca de dez minutos; o evento todo dura de uma a duas horas, dependendo do número de cantadores. Enquanto um canta, os outros ficam sentados no fundo do palco ou na platéia. Eis aqui uma das especificidades do cururu em relação a outras formas de desafio: na embolada, por exemplo, os desafiantes cantam no esquema fala-resposta, e cada um canta uma estrofe. No repente também existe esse tipo de construção. No cururu, não: deve-se ouvir todo o improviso de um cantador 
Revista de Antropologia, São Paulo, USP, 2007, v. 50 No 1.

primeiro para depois responder. Isso faz que a dinâmica do conflito tenha um ritmo singular na medida em que a resposta não é imediata. A isso voltarei adiante. Por ora, é útil observar que, terminada a primeira rodada, volta-se ao primeiro cantador e se faz outra rodada que segue a mesma ordem da primeira; e esta segunda rodada, conforme mostrarei, é importantíssima porque é o momento de responder a possíveis provocações dos outros cantadores.

Apresento abaixo, como exemplo, a transcrição de um desafio entre dois cantadores: Narciso Correia e Zico Moreira. Esses são dois cantadores já lendários dentro do universo do cururu, sendo apontados como referências pelos atuais cantadores. ${ }^{6}$ Esse desafio foi gravado em disco nos anos 70, opondo somente dois cantadores, e é um bom exemplo do canto de pau trocado.

Dou a palavra a Narciso Correia:

Vou cantar o cururu

Carreira São João Batista

Peço licença pro povo

Obrigação de um repentista

(5) Eu aviso desde já

Eu vim lá do Paraná

Pra enfrentar um campeão paulista

Eu sou Narciso Correia

(...) sou motorista

(10) Cantador de cururu

Brasileiro e reservista

Eu gosto de cantoria

Quando eu entro na porfia

É impossível que eu desista 
Allan de Paula Oliveira. Quando se canta o conflito...

(15) Vou cantar contra o Moreira

Quero que o pessoal assista

Zico Moreira está fraco

Este é meu ponto de vista

Eu falo perante o povo

(20) Onde canta um galo novo

Galo velho abaixa a crista

Eu cheguei em Sorocaba

Que é a Manchester paulista

Encontrei Zico Moreira

(25) Estava olhando uma revista

Mas eu quero esclarecer

Caboclo não sabe ler

Ele fugiu de escola mista

Outro dia eu vi o Moreira

(30) Junto de dois palmeiristas

Ele estava de calção

Feito de um pano de lista

Jogador ele não é

Só tem inveja do Pelé

(35) Foi que ele abancou o esportista

Esse tal Zico Moreira

Foi um caboclo farrista

Na cidade de Tietê

Aquela terra benquista

(40) O caboclo gabiru

Parecia Jeca Tatu

Quando ele era lavourista 
Revista de Antropologia, São Paulo, USP, 2007, v. 50 № 1.

Agora em Sorocaba

Ele quer fazer conquista

(45) Todo mundo está sabendo

Que o Zico é (...)

Marreteiro de primeira

Esse tal Zico Moreira

É o campeão dos vigaristas

(50) O Moreira antigamente

Ele era getulista

Mas depois de um certo tempo

O Zico virou janista

Pra cantar e ganhar dinheiro

(55) O caboclo interesseiro

Já virou ademarista

O Zico era feiticeiro

Começou a fazer conquista

Mas a polícia deu em cima

Ele virou espiritista

(60) $\mathrm{O}$ caboclo não tem firmeza

Pois eu tenho na certeza

Que ele vira evangelista

Em seguida a resposta de Zico Moreira:

Esse Narciso Correia

É um cantante inteligente

Ele canta muito bem

Faz agrado a muita gente

(5) Sua fama é muito grande 
Allan de Paula Oliveira. Quando se canta o conflito...

E quem me falou não mente

Mas não sei o que acontece

Que a fama desaparece

Quando está na minha frente

(10) Escutei ele cantando

Compreendi perfeitamente

Diz que o frango quando canta

Deixa o galo descontente

Galo velho abaixa a crista

(15) Por ver tudo diferente

Por ver que um franguinho novo

Há três meses saiu do ovo

E está querendo ser valente

Eu fugi da escola mista

(20) Essas coisas não o mentem

Quatro anos eu estive lá

E já foi o suficiente

Eu guardei o meu diploma

Que eu tirei antigamente

(25) Está lá bem guardadinho

Para esfregar no focinho

Daquele que me desmente

O Narciso diz assim

Que eu sou um caboclo indecente

(30) Marreteiro e vigarista

Diz que eu logro muita gente

Uma vez logrei o tal

É por isso que ele sente 
Revista de Antropologia, São Paulo, USP, 2007, v. 50 № 1.

Por quinhentos mil cruzeiros

(35) Dei um bode e um carneiro

E um burro velho sem dente

Sem dizer que o frango novo

Está com a cabeça quente

Quer brigar com o galo velho

(40) Mas é impossível que agüente

Galho velho tem espora

Deixa o frango descontente

O que vai acontecer

É que o frango vai correr

(45) De medo que a espora entre

O Narciso é um cantador

Que canta divinamente

É o tal que canta tudo

$\mathrm{O}$ que vem na sua mente

(50) Mas é muito linguarudo

Pra falar dos inocentes

Além disso é meio louco

$\mathrm{Eu}(. .$.$) esse caboclo$

Pra pelar com água quente

(55) E agora eu descanso um pouco

Depois volta novamente

De novo Narciso Correia, dando início à segunda rodada:

Agora quero cantar

Ai, carreira do presumido 
Allan de Paula Oliveira. Quando se canta o conflito...

Ai, eu saí do Paraná

Já vim meio prevenido

(5) Por saber que eu vou cantar

E contra um cantador sabido

É o tal Zico Moreira

Que hoje vai passar canseira

Com esse meu verso batido

(10) Olhei na cara do Zico

Está muito desenxavido

Ai, com os olhos lá no fundo

E com esse testão lambido

Magricela desse jeito

(15) $\mathrm{Ai}$, vai tomar um coro sentido

Mas essa surra que eu vou dar

Começo no calcanhar

E arremato no pé do ouvido

E arrepare que eu sou gordo

(20) Que sou forte e sacudido

E sou duro e corajoso

Ai, pra todo sou decidido

Pra cantar verso trovado

$\mathrm{Ai}$, de ninguém me intimido

(25) Ai, no dia que eu apanhar

Eu largo mão de cantar

E vou pros Estados Unidos

Ai, se eu perder pra esse Moreira

$\mathrm{Ai}$, fico muito aborrecido

(30) Jogo dinheiro dobrado 
Revista de Antropologia, São Paulo, USP, 2007, v. 50 № 1.

Ai, se acaso for vencido

Sou campeão de cantoria

$\mathrm{Ai}$, pros lugares que eu tenho ido

Eu juro por Nossa Senhora

(35) Eu jogo meu diploma fora

Se um dia eu for vencido

Eu sou que nem um galo índio

Ai, que tenho couro cortido

E nem que bata como for

(40) Ai, nunca fica dolorido

Esse tal Zico Moreira

Ai, é um galo velho corrido

Ai, que há tempos saiu da rinha

Hoje é pior do que galinha

(45) Fica no ninho escondido

E me despeço vou-me embora

$\mathrm{Ai}$, porque o prazo está vencido

E digo minha gratidão

Ai, pro estranho e conhecido

(50) Já bati no cantador

$\mathrm{Ai}$, que ficou com o lombo ardido

E digo um viva pro Moreira

Outro viva pra bandeira

Do nosso Brasil querido

E uma vez mais, para finalizar o desafio, Zico Moreira:

Cada vez que a viola toca

Eu entro na hora exata 
Allan de Paula Oliveira. Quando se canta o conflito...

$\mathrm{O}$ violeiro é que começa

Ele mesmo que arremata

(5) Não tem rima que eu não cante

Nem verso que eu não rebata

Eu canto dando pancada

Alguém faz marmelada

Mas comigo é na batata

(10) Senhor Narciso Correia

Caboclo de cara chata

Se o meu olho está no fundo

Conforme você relata

Respectivo a algum defeito

(15) Eu acho que nós empata

Seu nariz esparramado

Testa de amolar machado

Boca de caçar barata

Diz que se apanhar de mim

(20) Vai fugir na mesma data

Some pros Estados Unidos

Mas que caboclo pirata

Por favor não vá pra lá

Que o americano mata

(25) Lá não usa carrocinha

Lá estão dando bolinha

Pra acabar com os vira-lata

Não quero que você diga

Que eu sou pessoa ingrata

(30) Muitas vezes cantamos contra 
Revista de Antropologia, São Paulo, USP, 2007, v. 50 No 1.

E eu tenho sido democrata

Hoje eu não vou lhe dar chance

Vou the dar uma gravata

Você já gozou bastante

(35) Mas de hoje por diante

Vou acabar com sua mamata

Narciso é do Paraná

Mora na beira da mata

Numa casinha modesta

(40) Na beira de uma cascata

Quando tem anel de estanho

Ele fala que é de prata

Diz que é paranaense

Eu acho que ele é cearense

(45) Porque tem a cabeça chata

Cururu pra ser bonito

É preciso que combata

Eu gosto de responder

Cantador que me maltrata

(50) Sou que nem caboclo antigo

Que anda de par à cata

Cantador que afirme o pé

Porque o nó que o Zico der

Cantador nenhum desata

(55) E nesse ponto agora eu paro

Vou guardar minha chibata 
Allan de Paula Oliveira. Quando se canta o conflito...

Esse desafio entre Zico Moreira e Narciso Correia pode ser tomado como uma espécie de "mito de referência" do cururu na medida em que apresenta os principais elementos desse tipo de desafio, assim como é metapoético ao fazer referências de como deve ser a cantoria. Esse desafio, portanto, servirá para uma descrição da dinâmica e da natureza do conflito no cururu. Antes, porém, gostaria de apontar uma contextualização do cururu enquanto prática musical.

O cururu é indicado na literatura sobre música brasileira como uma prática caipira, justamente por ser praticado nas áreas de colonização paulista onde a figura do caipira aparece como importante marca de identidade. ${ }^{8} \mathrm{O}$ caipira é apontado como o símbolo de toda uma região - o Centro-Sul do Brasil -, descrita numa vasta literatura em termos de regras de sociabilidade e práticas próprias. Antes de tudo, o caipira e suas práticas são símbolos do rural na sociedade brasileira. Em outro texto (Oliveira, 2004), descrevi como a construção da nação no Brasil teve no debate urbano-rural um de seus principais eixos, desde o século XIX até meados dos anos 70, quando o país passa a ser considerado predominantemente urbano. Nessa discussão sobre a nação, apontei algumas matrizes teóricas que orientaram discursos relativos ao mundo rural, cada um lhe dando um valor diferente. Um desses discursos vê no mundo rural o espaço de práticas não racionais, tais como visão mágica do mundo, técnicas rudimentares de trabalho, relações paternalistas, assim como outras formas de percepção do tempo e do espaço. ${ }^{9}$ Nesse caso, o rural é valorado negativamente, havendo aí uma certa idéia fatalista: esse lado mais arcaico do Brasil sumirá com o tempo devido à marcha da racionalização. ${ }^{10}$

Pois foi a partir dessa perspectiva que saíram os trabalhos mais importantes sobre as formas de sociabilidade e práticas caipiras. Gostaria de citar dois deles. Cândido (1981) faz, com base em uma etnografia numa 
Revista de Antropologia, São Paulo, USP, 2007, v. 50 No 1.

comunidade próxima a Piracicaba, uma descrição sobre práticas e relaçôes sociais no universo caipira, apresentando esse universo como tradicional, ou seja, como resistente a transformaçôes bruscas. ${ }^{11}$ Ele aponta a importância de elementos como a sazonalidade, o parentesco e, mais importante, das relaçôes vicinais e de reciprocidade. Cândido descreve de que forma, no meio caipira, práticas sociais como o mutirão, em que vizinhos se reúnem para fazer um serviço a um terceiro, que fica obrigado a devolver o trabalho em ocasióes futuras, são centrais como modos de sociabilidade. A prestação de serviços recíprocos é, portanto, uma importante forma de relação social e é central na constituição do status de pessoa, de sua face ou, ainda, de sua honra no universo caipira, na medida em que essas são construídas com a participação do indivíduo dentro desse universo da reciprocidade. Fugir a isso constitui um risco junto à comunidade, um movimento negativo no sentido da honra e da pessoa.

Partindo exatamente da importância da reciprocidade dentro do universo caipira, Carvalho Franco (1997) analisa o lugar da violência e dos conflitos nesse universo. Analisando processos-crimes no Vale do Paraíba do século XIX, a autora comenta que a violência seria "uma forma rotinizada de ajustamento nas relações de vizinhança” (id., p. 30). Carvalho Franco usa isso para discordar da idéia de que relaçôes vicinais e de reciprocidade se baseiem apenas na conjunção social. Ela revela como não estão excluídos momentos de disjunção social, nos quais uma simples brincadeira pode transformar um mutirão numa briga generalizada. Interessante observar que a autora não apresenta um universo em desequilíbrio, pelo contrário. Apenas mostra como o equilíbrio social tem em seu interior momentos de tensão e disjunção ou, ainda, como tensão e solidariedade são conjugadas. Assim, para ela, "essa violência atravessa toda a organização social, surgindo nos setores menos regulamentados da vida, como as relaçôes lúdicas, e projetando-se até a codificação dos valores fundamentais da cultura” (id., p. 27). Em certa 
Allan de Paula Oliveira. Quando se canta o conflito...

medida, a violência, que Carvalho Franco analisa no universo caipira como costumeira e institucionalizada, funda-se no próprio lugar da reciprocidade: devolvem-se não somente os favores, mas também as ofensas.

O cururu, dessa forma, aparece como uma prática lúdica em um meio social onde valores como vicinalidade e reciprocidade são centrais. E, de fato, ainda hoje o cururu é praticado, sobretudo, em festas comunitárias realizadas no interior de São Paulo, festas organizadas por vizinhos (para comemorar um aniversário, a inauguração de uma praça de esportes ou de uma creche), nas quais cada um contribui com alguma coisa. ${ }^{12}$ Assim a reciprocidade, pode-se dizer, envolve o cururu, e sua prática sinaliza exatamente esses momentos de ação comunitária. Mas isso não significa, e neste ponto estou de pleno acordo com Carvalho Franco, que as disjunções e os conflitos não estejam presentes. Pelo contrário, o cururu é a ritualização de um conflito. Ele próprio é um conflito. Vale refletir sobre a natureza desse conflito.

Assinalei em negrito, no segundo canto de Zico Moreira, alguns versos que me parecem esclarecedores. Um deles diz: "cururu pra ser bonito, é preciso que combata". Esses versos sintetizam o canto de pau trocado, a modalidade em que se provoca, com gracejos e gozações, um outro cantador. "É preciso bater", dizem os cantadores, e o prestígio de um cantador é tanto maior quanto mais ele participa do pau trocado, não fugindo da bateção. Percebe-se aqui que há uma obrigatoriedade da doação - o bom cantador, aquele que tem honra, é obrigado a dar seu verso batido. Em seguida, Zico Moreira canta "eu gosto de responder, cantador que me maltrata”: eis a contrapartida da dádiva, uma contradádiva. Da mesma forma, não responder a uma provocação no cururu é fugir do pau trocado, o que desonra o cantador. Vê-se como tanto a ação como a reação são obrigatórias no pau trocado e, conforme afirmei, o status de pessoa, sua face (na terminologia de Erwing Goffman), sua honra (Pierre 
Revista de Antropologia, São Paulo, USP, 2007, v. 50 No 1.

Bourdieu), seu prestígio dependem de sua participação nesse jogo de reciprocidade. Ademais, o cururu também exige que os cantadores levem na esportiva as provocaçōes que recebem. Esse "levar na esportiva" é o elo entre o dar e o retribuir, elo que Mauss (2004) já havia preconizado em sua análise da dádiva como a "obrigação de receber". ${ }^{13}$

O cururu, portanto, é também um ritual da reciprocidade, e suas regras parecem ter sido escritas por Marcel Mauss: a obrigatoriedade de dar, receber e retribuir. Trata-se, desse ponto de vista, de um fenômeno similar a tantos outros, analisados por diferentes antropólogos, que têm na reciprocidade seu eixo central: potlach, kula, vendetas, brigas de família, troca de mulheres. Enfim, uma atualização desse princípio básico da socialidade humana - nos termos de Lévi-Strauss (2004), a troca. E mais, trata-se de uma troca que aparece estruturada em torno de um conflito ou, ainda, trata-se de um conflito que tem na troca seu eixo central. Essa troca, em vez de colares, conchas ou mulheres tem nas palavras seu bem precioso. Uma troca de palavras pela qual dois oponentes digladiam entre si e procuram afirmar-se um perante o outro. Contudo, se isso permite observar a natureza do cururu, pouco diz sobre suas especificidades e sua dinâmica. Para isso, é preciso chegar um pouco mais próximo e ver como o cururu tinge com tintas próprias tanto o tema da troca quanto o do conflito. Volto então ao desafio entre Zico Moreira e Narciso Correia.

O desafio transcrito mostra perfeitamente o jogo entre dar e retribuir: cada um procura responder todas as provocações feitas, devolvendo-as ao adversário. Este é um ponto importante a ser observado: não basta responder somente. É preciso responder e dar "algo mais", pois a resposta tem um caráter de dádiva também. Responder somente significaria romper o laço, interromper o jogo, e não é esse o caso. Pelo contrário, no cururu, os cantadores procuram manter a tensão no ar de 
Allan de Paula Oliveira. Quando se canta o conflito...

modo que o desafio se perpetue. É um tipo de conflito que produz uma espécie de transe no tempo: sempre fica a expectativa da fala futura, da próxima assertiva ou resposta. Aqui ocorre algo similar ao que Viveiros de Castro e Carneiro da Cunha (1985) descreveram para a vingança tupinambá: não interessa interromper o ciclo dos conflitos e sim perpetuá-lo, pois a ausência do inimigo impossibilita a própria cantoria e, assim, a constituição de si como cantador. Basta ver um dos versos com que Zico Moreira fecha o cururu: "sou que nem caboclo antigo, que anda de par à cata”. ${ }^{14}$ Por isso, no cururu, nunca há o golpe final, o nocaute, a última palavra, há sempre a expectativa de futuro.

As provocações tecidas por Zico Moreira e Narciso Correia em torno da idéia de galo velho/galo novo/frango/galinha ilustram bem este último ponto. O tema vai se desenrolando ao longo dos improvisos e se tem a impressão de que sempre há ainda uma "carta na manga", uma provocação que foi guardada para o desenrolar do conflito. E, a cada elemento que entra nos improvisos, mais o conflito vai se desenvolvendo. É por isso que chamei a atenção no início do texto para uma especificidade importante do cururu: o fato de as respostas serem posteriores a todo improviso individual. É preciso primeiro ouvir toda a cantoria alheia antes de responder. Isso produz uma expectativa que movimenta os participantes e a platéia: "o que será que fulano vai responder?" ou, nos cururus atuais com cantadores que costumam fugir do pau trocado, "será que fulano vai responder?". Esse conflito que tende a se alargar no tempo, ou ainda o jogo que é produzido com a temporalidade, constitui uma característica do cururu enquanto conflito. ${ }^{15}$

Caillé (2002, p. 109) chama a atenção para o fato de as trocas lingüísticas serem sempre de cunho agonístico, verdadeiros potlachs, nos quais o bem dado procura se impor sobre o outro e anular sua possibilidade de resposta. Seja na forma de conversação, seja na forma de disputa oratória, a troca de palavras acaba por criar uma situação em que, em 
algum ponto, a troca é suspensa e alguém detém o domínio da situação. A meu ver, o cururu é, sim, um conflito baseado na troca de palavras, mas seu cunho não é agonístico, exatamente porque mantém a possibilidade da interação indefinidamente. De certa forma, o único limite é a cantoria do adversário: pára-se de cantar quando tudo tiver sido respondido. Se a platéia tiver paciência, ou se o técnico de som deixar, os cantadores improvisam ad infinitum. ${ }^{16}$

No entanto, concordo com Caillé (id., p. 120) quando ele afirma que, nas disputas oratórias, há um controle das palavras e que se utiliza cada uma no momento certo. Isto no cururu me parece central: há o momento certo de colocar as provocaçóes e usar recursos como a ironia, o gracejo em torno de certas características físicas, dentre outros. Há, então, uma economia das palavras que leva os cantadores a dosarem esses bens preciosos no cururu, utilizando-as na hora certa e na medida certa. $\mathrm{O}$ cururu aponta para um universo em que a constituição da pessoa se dá pelo equilíbrio na troca: critica-se o cantador que não bate, como também o cantador que bate demais, que estende demais seu improviso (repare o leitor que os improvisos de Zico Moreira e Narciso Correia têm praticamente o mesmo tamanho) e não deixa os outros cantarem. Tal equilíbrio exige o uso do tempo: assim como o lutador que administra a luta mas nunca dá o "golpe final", o cururu também exige um uso equilibrado das forças. $\mathrm{O}$ ataque não visa encerrar o embate, mas provocar a resposta. Uma vez mais, fica evidente a tendência do cururu: um tipo de conflito que procura se estender no tempo.

Essa economia centrada no equilíbrio produz também uma hierarquia entre os cantadores: o bom cantador é aquele que sabe usar a palavra na hora certa e no tempo certo. Aqui o cururu reflete as colocaçôes de Bourdieu (1996), para quem as trocas lingüísticas expressam não somente hierarquias anteriores (a posição social do falante leva-o para formas e conteúdo de falas) mas as atualizam. No entanto, tal hierarquia 
Allan de Paula Oliveira. Quando se canta o conflito...

no cururu consiste num ponto extremamente delicado na medida em que ela não é explícita pelos cantadores e nenhum deles se admite pior que outro. A tendência é ninguém reconhecer uma possível vitória de outro cantador. Aqui as possibilidades analíticas se multiplicam. Por exemplo, posso pensar tal dado à luz de Carvalho Franco (1997), que vê no mundo caipira uma tendência à indiferenciação, uma resistência a qualquer centralização hierárquica. Seus argumentos são muito similares aos de Clastes (2003) sobre a suposta ausência de chefias no mundo guarani: divisão do trabalho incipiente, produção voltada apenas para a subsistência, predomínio de relações de parentesco em detrimento das de dominação. O cururu, assim, seria um reflexo dessa indiferenciação do mundo social caipira.

Porém, há no cururu uma hierarquia, não no sentido do reconhecimento do "comando" de alguém, mas no do reconhecimento de que alguém tem mais palavras a oferecer ou, ainda, na predileção por certos cantadores como desafiantes. Há atualmente em Piracicaba um cantador que reúne consigo diversos outros e raramente há um cururu sem a sua presença. Esse cantador poderia ser definido como um ótimo doador de palavras: todos querem cantar com e contra ele. Contudo, isso só é observável no nível dos comportamentos e não nos discursos. Ninguém indica esse cantador como melhor, mas todos o procuram. Nesse sentido, o cururu não aponta para um mundo sem hierarquia, mas para um modo de sociabilidade em que a hierarquia, além de não ser verbalizada, é vivida muito mais como a capacidade de um indivíduo doar e redistribuir palavras do que a possibilidade de um indivíduo ser declarado como superior a outros. ${ }^{17}$ Ouso dizer que aqui a "chefia" é uma ação e não um estado: age-se como "chefe" e não se é declarado chefe. Autoproclamar-se chefe, no universo dos cantadores, não teria o menor sentido - é preciso agir como tal. ${ }^{18}$ Para isso, deve-se cantar e cantar bem, pois a cantoria é a afirmação da posição individual dentro do grupo. 
Vê-se, aqui, como o cururu é um tipo de conflito que combina horizontalização e verticalização sociais. De um ponto de vista, o ato de cantar horizontaliza pessoas, apresenta-as como iguais. De outro (o dos cantadores), a prática do cururu é uma forma de hierarquização. A esse ponto voltarei adiante.

Até agora procurei mostrar de que modo o cururu pode ser visto como um conflito não agonístico, baseado na troca de palavras organizado em torno de um jogo em que a reciprocidade é vivida com equilíbrio e em que se procura estender a troca ao longo do tempo e em que verticalizações hierárquicas são vivenciadas na capacidade de redistribuição da palavra, não sendo estabelecidas publicamente. Por fim, vale observar como se constrói a idéia de pessoa nesse universo - sigo aqui a proposta de Goldman (1998) de que a antropologia deve buscar os modos de subjetivação ou, ainda, os modos como se constrói a noção de pessoa nos diferentes universos sociais.

Afirmei que, acima de tudo, o estatuto de pessoa no cururu é dado pela participação do cantador no universo da reciprocidade cantada: deve-se provocar o adversário e responder as provocaçóes feitas. Um cantador tem mais prestígio e honra quanto mais inserido estiver nesse circuito de trocas, quando não fugir da cantoria, da bateção, do pau trocado, da porfia. Nesse sentido, Zico Moreira e Narciso Correia são exemplares: não somente fazem o pau trocado como em seus cantos afirmam que gostam da porfia e que ninguém pode com eles. Assim, percebe-se também como o improviso no cururu é feito no sentido de afirmar a própria face, de cantar as próprias qualidades, de se impor.

Ao mesmo tempo, há um movimento oposto que ocorre em paralelo a essa auto-afirmação: além de cantar a si próprio, o cantador denigre o adversário. A si, o canto; ao outro, uma decantação. O objetivo aqui é negar a face do adversário, evitar sua sublimação. Nesse ponto, o recurso ao humor aparece como um dos elementos mais utilizados. Essa 
Allan de Paula Oliveira. Quando se canta o conflito...

faceta do humor - como recurso que provoca uma verticalização - não é muito explorada pela literatura sobre o tema. ${ }^{19}$ Textos clássicos, tais como Bergson (2001) e Bahktin (2000), apontam somente a função horizontalizante do humor, capaz de subverter a ordem social. Douglas (1975, p. 155) afirma o mesmo ponto, vendo no humor um canal de instituição da communitas, tal como descrita por Victor Turner, ou seja, como um modo de relação social oposto à hierarquia e no qual a reciprocidade é central. Pois no cururu o humor não indica somente horizontalização, mas também aponta para uma tentativa de rebaixamento do outro, de negação do adversário. No cururu, o riso é estrutural: é o modo de subjugar o adversário. Se é necessário combater para que o cururu seja bonito, é assim que se combate, fazendo rir - e nisso Zico Moreira e Narciso Correia são exemplares. Ao adversário cabe levar na esportiva. A partir daí, não me parece descabido pensar na relação entre os cantadores como análoga do que Radcliffe-Brown (1973) chamou de "parentesco por brincadeira". A própria definição de tal expressão sugere essa aproximação:

O que se entende pelo termo "parentesco por bricandeira" é a relação entre duas pessoas na qual uma é, por costume lícito e em alguns casos obrigatório, levada a importunar ou a zombar de outra, que, por sua vez, não pode ficar aborrecida. (Radcliffe-Brown, 1973, p. 115)

A meu ver, a analogia é clara. E mais, Radcliffe-Brown possibilita pensar o humor no cururu como um modo de equilíbrio entre conjunção e disjunção social. Ao mesmo tempo em que aproxima as pessoas, cria distância entre elas, sendo uma forma particular de estruturação social. ${ }^{20} \mathrm{Na}$ verdade, joga-se com a hierarquia: a brincadeira, o gracejo permitem horizontalizar as relações ao mesmo tempo em que estabelecem diferenças de posição. Nesse caso, vê-se como o humor pode ser 
Revista de Antropologia, São Paulo, USP, 2007, v. 50 No 1.

uma estratégia de denegação do outro, mas que mantém em um certo grau a conjunção social, já que os cantadores estão sempre nas mesmas festas, nos mesmos espaços.

Há ainda outras estratégias para decantar o outro. Nada me chama mais atenção do que o uso da terceira pessoa no canto, canta-se como se o adversário não estivesse ali, como se fosse um ausente: "Esse Narciso Correia", "esse tal Zico Moreira”. O outro é um ele, cujo antagonismo é fundamental, mas que é transformado em objeto, alguém de quem se fala. Caillé (2002, p. 120) comenta que em disputas oratórias a honra vem da defesa da própria face, de sua afirmação, mas também da transgressão do domínio que é interdito, a face alheia. Assim, o cantador honrado, de prestígio, é aquele que não somente se afirma, mas também aquele que ataca, que deixa o outro com lombo ardido, porém, como se este outro não estivesse ali. ${ }^{21}$ No entanto, para transformar o outro num "ele impessoal", é necessária a presença de um interlocutor - segundo Caillé (id., p. 107), um "tu" para quem se fala sobre o "ele" ausente. Quem seria este tu no cururu? A audição da gravação do desafio transcrito começa e termina com ele: o público, a platéia. ${ }^{22}$

A presença de uma platéia denota o traço que permite ao cururu conjugar todos os aspectos descritos anteriormente: ele é também uma performance. Poderia tratá-lo como uma simples ritualização de um conflito, como nas análises dos dramas rituais propostos por Gluckman (1963). No entanto, as análises desse autor, se nos permitem pensar o conflito como um elemento central na estabilidade de um grupo social, a ponto de ele ser ritualizado de tempos em tempos, pouco dizem sobre a dinâmica desses conflitos quanto à possibilidade de pensá-los como uma ação criadora. Gluckman centra sua análise nos papéis sociais envolvidos no conflito e no efeito deste sobre a estrutura social. Aqui me interessa mais pensar o cururu como uma forma de práxis. Nesse senti- 
Allan de Paula Oliveira. Quando se canta o conflito...

do, a categoria performance, tal como vem sendo utilizada na antropologia desde os anos 70, parece-me uma ferramenta analítica adequada à análise do cururu. ${ }^{23}$

Langdon (1996) comenta que a performance pode ser vista como um modo de ação ritual que tem, entre outras, por característica o fato de ser enquadrada em termos de espaço e tempo. Assim, ao contrário dos conflitos rituais descritos por Gluckman, muito mais holistas no sentido de envolverem o todo social, a performance produz ações localizadas, cujo enquadramento é dado por marcas tais como "Era uma vez", "Você conhece aquela...", pela circunscrição da ação a um espaço definido - o palco -, e, mais importante, pela participação da platéia que, com aplausos, vaias e "oooohs", interfere na dinâmica da ação. Isso quer dizer que nem todo ritual pode ser lido como uma performance. Assim, o cururu pode ser visto como um conflito apresentado sempre como uma performance, em que há um espaço para os cantadores (geralmente um palco), um tempo certo para cada apresentação e em que aspectos como gestos, inflexão de voz, vestuário são fundamentais para a relação com o público. Este, conforme afirmei acima, é o "tu" da troca lingüística que é o cururu. É para ele que se canta. Ao mesmo tempo, a reação dele é responsável pela hierarquia velada que apontei: é pela reação do público que o cantador a que me referi como o principal de Piracicaba adquiriu esse status, já que suas apresentaçôes são as mais aplaudidas na cidade. ${ }^{24} \mathrm{O}$ público, dessa forma, aparece como uma espécie de "mediador" do conflito, e é em torno dele que giram as ações dos cantadores.

Uma ritualização performática de um conflito - esse é o modo como o cururu se apresenta enquanto cantoria. Nesse ritual, o eixo é claro: a troca de palavras. Em torno dela se organizam as práticas e a estrutura do evento. Em relação a outras formas de desafio cantado, a particularidade do cururu é seu uso do tempo. Em relação a outras formas de conflito, além do jogo com o tempo, há a economia de palavras baseada no 
Revista de Antropologia, São Paulo, USP, 2007, v. 50 No 1.

equilíbrio (caráter não agonístico), o caráter performático, bem como o uso de certas estratégias de denegação, tais como o humor.

Finalmente, é útil observar que mesmo o conceito de performance nos leva a um duplo ponto de vista na medida em que a performance tem sempre um ator e um espectador, e que, embora ambos participem da ação, não o fazem da mesma forma. Então, por um lado, pensar o cururu como uma ritualização performática do conflito é pensá-lo como um conflito domesticado e, em certa medida, é assim que ele aparece do ponto de vista da platéia. Aliás, esta é a função que Elias (1997) dá à arte no processo civilizatório: o espaço onde o homem pode liberar suas forças inconscientes. A arte, a manifestação lúdica, o esporte, nesse sentido, seriam espaços onde o conflito é permitido, embora enquadrado dentro de certos limites. O cururu, assim, é a ritualização do conflito num universo em que a violência e o conflito - o universo caipira - são formas rotineiras de ajustamento social, mas que são cada vez mais reprimidas pelo discurso da civilização e da racionalidade. Pode-se olhar, nessa perspectiva, o que significa o cururu para o público: a liberação momentânea de valores e desejos reprimidos, valores estes centrais na sociabilidade caipira, mas que a modernidade transformou em obsoletos.

As coisas mudam de perspectiva à medida que observamos o ponto de vista dos cantadores. Pode-se pensar também no que significa a performance de um conflito para quem canta o cururu no palco. Ali, o conflito, mesmo que ritualizado, é um meio de afirmação de si, de construção da pessoa, um meio de relação com o outro. Para estes, o conflito não é a sublimação de um desejo reprimido, mas a própria vida, a constituição do seu estar no mundo. O conflito, aí, aparece como uma afirmação de seus praticantes no mundo, um estar vivo, um ser. Sem a porfia ou um cantador que me maltrate, o mundo, se não perde muito de seu sentido, carece muito de sua graça. 
Allan de Paula Oliveira. Quando se canta o conflito...

\section{Notas}

1 Este texto é uma versão com muitas alterações do trabalho final apresentado à disciplina de Antropologia das Violências e dos Conflitos (segundo semestre de 2005). Agradeço ao professor dr. Theóphilos Rifiotis, ministrante da disciplina, e aos demais colegas que a cursaram. Muitas das idéias desenvolvidas aqui são desdobramentos de discussões da disciplina.

2 Para uma descrição mais detalhada do cururu, de sua história e de suas características estilísticas, conferir Oliveira (2004).

3 Para uma descrição desses campeonatos nos anos 40, o relato de Chiarini (1947) é uma excelente fonte documental.

4 Doravante, as expressões em itálico são aquelas usadas pelos próprios cantadores.

5 Apenas quando são solicitados nesse sentido é que os cantadores improvisam somente numa modalidade. Por exemplo, em festas religiosas, pedem-se apenas improvisos bíblicos. Por outro lado, hora ou outra, há gravaçōes de CDs de cururus. Neste caso, pede-se somente o pau trocado.

6 Os "cantadores de cururu" é um grupo composto de homens na faixa de idade entre 55 a 75 anos. Em 2003, durante meu trabalho de campo, não vi nenhum cantador "jovem" e nenhuma mulher que cantasse, embora na literatura haja referências a mulheres e adolescentes cantando cururu nos anos 40 e 50. Conferir, para essas referências, Chiarini (1947).

7 Zico Moreira faleceu, em 2002, aos 101 anos e, quando dessa gravação, contava com quase 80 anos. Quanto à transcrição, mantive o léxico-padrão da língua portuguesa e não transcrevi as inflexôes prosódicas devido ao sotaque. Algumas palavras, o leitor verá, são adaptadas para a carreira, de modo a possibilitar a rima. Assim, palmeirense (torcedor da Sociedade Esportiva Palmeiras, equipe de futebol de São Paulo) é cantado palmeirista. Algumas palavras não puderam ser transcritas por serem incompreensíveis, sendo anotadas com (...). Os números indicam os versos para facilidade de exposição. A transcrição foi feita a partir da gravação em disco realizada nos anos 70 .

Um dado importante a ser observado é que toda a análise desenvolvida aqui levou em conta apenas as palavras cantadas no cururu, relegando a um segundo plano sua música. Esta, porém, também traz questôes centrais para o entendimento do cururu enquanto conflito. Porém, preferi aqui enfatizar somente as letras por en- 
Revista de Antropologia, São Paulo, USP, 2007, v. 50 No 1.

tender que é nesse plano que as questôes que me interessavam no momento da construção deste texto estavam inscritas. Para uma problematização da separação letra-música, conferir Menezes Bastos (1996). Para uma primeira análise da música do cururu, conferir Oliveira (2004).

8 Para essa literatura, conferir Oliveira (2004). Pode-se citar, como exemplo, trabalhos de Câmara Cascudo e Mário de Andrade. Nas ciências sociais, por exemplo, conferir Brandão (1981).

9 Uma das fontes teóricas desse discurso é Max Weber. Assim, baseado em Weber, é que Sérgio Buarque de Holanda tinge o rural em Raizes do Brasil. Trabalhos como o de Carvalho Franco (1997) mantiveram essa tradição teórica. Porém, vale notar que Weber foi lido juntamente com Marx, produzindo uma bricolage teórica que dá muito do sabor de alguns textos sobre a sociedade brasileira nos anos 40 e 50 . Em alguns casos, no lugar de Weber, outras fontes foram usadas, como os estudos de ecologia urbana da Escola de Chicago. É o caso, por exemplo, do trabalho de Cândido (1981).

10 O que seria, de certa forma, um dos pressupostos dos estudos de comunidade, tais como praticados no Brasil entre os anos 40 e 70. A idéia era "devemos estudar antes que acabe". Sobre esses estudos de comunidade, conferir os comentários críticos de Woortmann (1995).

11 Não que Cândido negue essas transformaçōes. Pelo contrário, seu trabalho mostra - e, a meu ver, antecipando diversas abordagens da antropologia - como essas transformaçōes são adaptadas ao modo de vida caipira. Curiosamente, o trabalho de campo que propiciou a Cândido a elaboração de seu livro foi inicialmente previsto como um estudo sobre o cururu na comunidade de Bofete (SP). Já em campo, o autor percebeu que as transformaçôes dos meios de vida seriam um tema mais interessante.

12 E não somente o cururu. Outras práticas musicais, tais como o catira e a canaverde, também são apresentadas nessas festas. Além disso, o cururu integrou-se a um universo mais amplo e que é central na vida dos moradores do interior de São Paulo: a música caipira. Nos anos 40, o improviso deu lugar a letras fixas, surgindo daí o cururu-canção que, do improvisado, só mantém o ritmo da viola. Menino da porteira é um exemplo de cururu-canção. Sobre o cururu e a música caipira, conferir Nepomuceno (1999) e Oliveira (2004). 
Allan de Paula Oliveira. Quando se canta o conflito...

13 Isso vem mudando. De uns vinte anos para cá, o pau trocado tem seu espaço cada vez mais reduzido no cururu de Piracicaba. Atualmente, ele aparece em alguns versos no meio da cantoria, e esta é destinada muito mais a tecer loas ao público (improvisa-se com o nome das pessoas da platéia). Há, portanto, cantadores atuais que não praticam o pau trocado, embora sejam criticados e diminuídos por isso. Mesmo assim, é interessante observar também que o discurso dos cantadores ainda enfatiza a importância do pau trocado, ou seja, ele ainda é um critério para classificaçôes nativas. Por isso, escolhi como "mito de referência" um desafio em que essa modalidade aparece em toda sua plenitude. Por isso também se escutam em Piracicaba muitas pessoas dizendo que o "cururu acabou", exatamente porque não se faz mais o pau trocado como antes. Pode ser - e isto é uma conjectura - que, dentro de alguns anos, ele não seja mais referência para a prática do cururu.

14 Em abril de 2003, pude conversar com Nhô Chico, uma das lendas do cururu de Piracicaba, ainda vivo. Com mais de 80 anos, Nhô Chico era o "caçula" de uma geração de cantadores que fez história no cururu entre os anos 40 e 70 , e que incluía, além dele, os já citados Zico Moreira (contra quem Nhô Chico cantou várias vezes), Narciso Correia, Parafuso, Benedito Silva, Luizinho Rosa, entre outros. Ficaram famosos os desafios entre Nhô Chico e Parafuso, e alguns foram gravados em discos pela Funarte nos anos 70 como exemplo de folclore do interior de São Paulo. Quando falamos sobre o cururu, ele me disse que não cantava mais desde a morte de Parafuso. Segundo ele, a graça era cantar contra o Parafuso. Sem este, não havia mais sentido.

15 Característica que não é unicamente do cururu, diga-se de passagem. O mesmo "modo de conflito" - que joga com o tempo - aparece, por exemplo, na prática de determinados esportes. Por exemplo, diz-se que o bom lutador de boxe é aquele que administra a luta, aplicando golpes estratégicos até o momento de dar o "golpe final", o nocaute. Esse modo de lutar em que se administra a luta, evitando, no entanto, encerrá-la, parece-me muito próximo do que ocorre no cururu. A diferença é que neste não há o "golpe final". Sobre a idéia de "administrar a luta" no boxe, conferir Wacquant (2003, pp. 102-7).

16 O que fica evidente no fim da cantoria de Narciso Correia quando ele diz "que o prazo está vencido" e é necessário parar. Não duvido que ali houvesse um técnico de som controlando o tempo. Eu mesmo vi isso diversas vezes em cururus apre- 
Revista de Antropologia, São Paulo, USP, 2007, v. 50 № 1.

sentados em programas de rádio em Piracicaba e pude perceber como o uso do tempo, para os cantadores, é uma questão importante.

17 Tangencio aqui uma profunda discussão que tem envolvido os estudos sobre reciprocidade no sentido de apontar sua relação com a idéia de hierarquia, ou seja, de não tomá-las como antitéticas. Lévi-Strauss (1996, p. 188) já apontava essa necessidade ao comentar que os teóricos clássicos da reciprocidade (Mauss, RadcliffeBrown e Malinowski) haviam relegado os fenômenos de assimetria (ou seja, hierarquia) a segundo plano. O texto de Lévi-Strauss "As organizações dualistas existem?" é uma tentativa de combinar analiticamente estruturas de comunicação (reciprocidade) com estruturas de subordinação (hierarquia). Clastres (2003), ao analisar a chefia guarani também aponta para a correlação entre reciprocidade e hierarquia. Para uma revisão dessa discussão, e apontando para o que ele chama de "reciprocidade hierárquica", conferir Lanna (1996).

18 Se a hierarquia não é proclamada publicamente, há uma nítida tendência em se denegar a posição alheia. Conversar com um cantador de cururu era um exercício de intrigas. "Sabe, professor, fulano não pode cantar comigo não. Ele não canta nada. Viu só aquilo que ele disse? Isto é coisa que se cante" era o tipo de comentário que eu ouvia sempre. Tais comentários, contudo, eram sempre feitos de modo privado. Voltarei a esse ponto adiante.

19 Para uma análise da literatura sobre o humor, com reflexōes sobre a abordagem da antropologia, conferir Driessen (1997).

20 É interessante observar que, fora do palco, os cantadores de cururu não brincam uns com os outros, havendo, inclusive, relações de evitação.

21 O que me faz pensar sobre as fofocas e intrigas que eu ouvia de um cantador sobre o outro. Não será essa prática da fofoca um outro exercício desse tipo de negação da face do outro? Para uma discussão sobre fofocas, intrigas e sociabilidade, conferir Douglas (1999).

22 Gastaldo (2005) descreve algo similar com base na etnografia realizada em botecos de Porto Alegre sobre o modo como torcedores de times rivais se reúnem para assistir a jogos de futebol pela TV. Segundo ele, durante as partidas, um torcedor xinga o time adversário como se não houvesse ninguém da torcida adversária presente, e é comum "xingar olhando somente a TV". Esses xingamentos, de acordo com o autor, são feitos para todos e para ninguém. 
Allan de Paula Oliveira. Quando se canta o conflito...

23 Para uma espécie de "resumo do estado da arte" nos estudos sobre performance, conferir Langdon (1996).

24 Sua popularidade o transformou em vereador.

\section{Bibliografia}

ARAÚJO, Alceu Maynard de

1964 Folclore nacional: danças, recreação e música, São Paulo, Melhoramentos.

BAHKTIN, Mikail

2000[1965] A cultura popular na Idade Média e no Renascimento: o contexto de François Rabelais, São Paulo, Annablume.

BERGSON, Henry

2001[1899] O riso: ensaio sobre a significação da comicidade, São Paulo, Martins Fontes.

BOURDIEU, Pierre

1996 A economia das trocas lingüisticas: o que falar quer dizer, São Paulo, Edusp.

BRANDÃO, Carlos Rodrigues

1981 Sacerdotes da viola: ritos do catolicismo popular em São Paulo e Minas Gerais, Petrópolis, Vozes.

CAILLÉ, Alain

2002[1994] "A dádiva de palavras: o que o dizer pretende dar", in MARTINS, Paulo Henrique, $A$ dádiva entre os modernos: discussão sobre os fundamentos e as regras do social, Petrópolis, Vozes.

CÂNDIDO, Antônio

1881[1964] Os parceiros do Rio Bonito: estudo sobre o caipira paulista e as transformaçôes do seu meio de vida, São Paulo, Duas Cidades.

CARVALHO FRANCO, Maria Sylvia

1997[1969] Homens livres na ordem escravocrata, São Paulo, Editora da Unesp. 
Revista de Antropologia, São Paulo, USP, 2007, v. 50 No 1.

CHIARINI, João

1947 "Cururu", Revista do Arquivo Municipal, ano 13, vol. CXV, jul.-set., São Paulo, pp. 81-198.

CLASTRES, Pierre

2003[1962] “Troca e poder: filosofia da chefia indígena”, in A sociedade contra o Estado, São Paulo, Cosac\&Naify, pp. 43-63.

DOUGLAS, Mary

1975 [1970] "Jokes", in Implicit Meaning: Selected Essays in Anthropology, London, Routledge. 1999 "Os Lele revisitados: acusações de feitiçaria à solta", Mana-Revista de Antropologia Social, Rio de Janeiro, 5(2): 7-30.

DRIESSEN, Henk

1997 "Humor, riso e campo: reflexões da antropologia", in BREMMER, Jan \& ROODENBURG, Herman (orgs.), Uma história cultural do humor, Rio de Janeiro, Record.

ELIAS, Norbert

1997 Oprocesso civilizatório 2: uma sociogênese do Estado, Rio de Janeiro, Jorge Zahar.

GASTALDO, Édison

2005 "O complô da torcida: futebol e performance masculina nos bares", Horizontes Antropológicos, Porto Alegre, vol. 11(24): 107-23.

GLUCKMAN, Max

1963 "Rituals of rebellion in South-East África", in Order and Rebellion in Tribal Africa, Londres, Cohen \& West.

GOLDMAN, Márcio

1998[1994] "Antropologia das sociedades complexas", in Alguma antropologia, Rio de Janeiro, Relume-Dumará.

LANGDON, Esther Jean

1996 "Performance e preocupaçōes pós-modernas em Antropologia", Antropologia em Primeira Mão, Florianópolis, 11. 
Allan de Paula Oliveira. Quando se canta o conflito...

LANNA, Marcos

1996 "Reciprocidade e hierarquia", Revista de Antropologia, São Paulo, vol. 38.

LÉVI-STRAUSS, Claude

1996[1952] “As organizações dualistas existem?”, in Antropologia Estrutural, Rio de Janeiro, Tempo Brasileiro, pp. 155-89.

2004[1950] "Introdução à obra de Marcel Mauss", in MAUSS, Marcel, Sociologia e antropologia, São Paulo, Cosac\&Naify.

MAUSS, Marcel

2004[1924] "Ensasio sobre a dádiva", in Sociologia e antropologia, São Paulo, Cosac\&Naify.

MENEZES BASTOS, Rafael José de

1996 "A origem do samba como invenção do Brasil. (Por que as cançôes têm música?)", Revista Brasileira de Ciências Sociais, Caxambu-MG, ano 11, n. 31, jun.

NEPOMUCENO, Rosa

1999 Música caipira: da roça ao rodeio, São Paulo, Editora 34.

OLIVEIRA, Allan de Paula

2004 O Tronco da Roseira: para uma antropologia da viola caipira, Florianópolis, dissertação em Antropologia Social, Universidade Federal de Santa Catarina.

RADCLIFFE-BROWN, A. R.

1973[1940] "Parentescos por brincadeira", in Estrutura e função na sociedade primitiva, Petrópolis, Vozes.

SIMMEL, Georg

$1978[\mathrm{~s} / \mathrm{d}] \quad$ "A natureza sociológica do conflito", in MORAES FILHO, Evaristo (org.), Sociologia, São Paulo, Ática.

VIVEIROS DE CASTRO, Eduardo \& CARNEIRO DA CUNHA, Manoela

1985 "Vingança e temporalidade entre os Tupinambás", Anuário Antropológico, Brasília, 86 
Revista de Antropologia, São Paulo, USP, 2007, v. 50 No 1.

WACQUANT, Loïc

2003[2001] Corpo e alma: notas etnográficas de um aprendiz de boxe, Rio de Janeiro, Relume-Dumará.

WOORTMAN, Ellen

1995 Herdeiros, parentes e comadres: colonos no Sul, sitiantes no Nordeste, São Paulo, Hucitec.

\begin{abstract}
This text makes an analisis about the cururu, a kind of singing challenge typical from countryside of state of São Paulo, Brazil. Making a transcription of these challenges, it tries to point for questions about cururu's structure and performance, seen like a struggle between two singers that fight using singing words. At the same time, it sees like the cururu is a local updating of a social fact: the exchange. For this, it is possible to think about its characteristics in relationship with other kinds of singing challenges and making points about these social facts.
\end{abstract}

KEY-WORDS: cururu, singing challenges, reciprocity.

Recebido em janeiro de 2007, aceito em novembro de 2007. 